\title{
THE FINAL PHAEDRA CONFERENCE - ENFORC- ING PRIVACY: LESSONS FROM CURRENT IMPLEMEN- TATIONS AND PERSPECTIVES FOR THE FUTURE (CRACOW, 12 DECEMBER 2014)
}

\author{
DOMINIKA CENDROWICZ*
}

On 12 December 2014, in the Sheraton Hotel in Cracow, the conference Enforcing privacy: lessons from current implementations and perspectives for the future took place within the framework of the PHAEDRA project. The main aim of this conference was to present the final results of the PHAEDRA project. It should be emphasized here that PHAEDRA is an acronym for "Improving Practical and Helpful cooperation between Data Protection Authorities". The aforementioned project was implemented by the PHAEDRA Consortium which comprises four partners: Vrije Universiteit Brussel (Belgium), Trilateral Research \& Consulting (United Kingdom), Inspector General for Personal Data Protection (Poland) and Universidad Jaume (Spain). The project was funded by the European Commission under its Fundamental Rights and Citizenship programme. Moreover, it should be mentioned that the final PHAEDRA conference was organized by the Polish Inspector General for the Protection of Personal Data.

The conference was addressed to national data protection authorities, selected policy-makers, representatives of the academic community, nongovernmental organizations and members of the media. The organizers divided the conference into three thematic sessions: "European and International cooperation in enforcing privacy - state of play", "Privacy enforcement in practice - International experiences in real life case handling" and "European and International cooperation in enforcing privacy - expectations and solutions for a strengthened co-operation". The main aim of each session was to summarize the results of the PHAEDRA project in the sphere of improving practical and helpful co-operation between data protection authorities.

The opening session was "European and International cooperation in enforcing privacy - state of play". This session was focused on the discussion surrounding existing legal frameworks for co-operation between na-

DOI: $10.1515 /$ wrlae-2015-0009

${ }^{*}$ Ph.D candidate at Institute of Administrative Science Faculty of Law, Administration and Economics University of Wroclaw; dominika.cendrowicz@prawo.uni.wroc.pl 
tional data protection authorities, co-operation in the field of best practices, accountability and enforcement, and lessons from areas other than data protection. The speakers emphasized the issues of findings and recommendations for improving cooperation and coordination at the end of the two-year PHAEDRA project.

Nicolas de Bouville (CNIL, France) was one of the first to take the floor in the first session with a presentation illustrating a very relevant problem concerning the right to be forgotten by everyone who uses the Internet. This right, in de Bouville's opinion, is imminently linked with a person's human dignity. Therefore, data protection authorities should pay particular attention to this issue. Piotr Drobek (GIODO Poland and Cardinal Stefan Wyszynski University) was the next speaker, who outlined three major problems of the entire PHAEDRA project (i.e. the problem of the right to participate in the PHAEDRA project). What is more, Drobek raised a very interesting question, namely, "why do we need a new legal basis in the field of data protection?" It should be emphasized that this question is very important for data protection authorities, especially in their everyday work.

The following speaker, Carman Baggaley from the Office of the Privacy Commissioner of Canada, pointed out seven roles of Ombudsman in the field of data protection, and illustrated roles and functions of data protection authorities. Baggaley subsequently asked the following question: "are data protection authorities regulators of data protection, or are they 'only' Ombudsmen?" Finally, Baggaley pointed out different types of cooperation in the field of data protection, and emphasized that it is good to create cooperation projects between data protection authorities because such cooperation is like building bridges between different countries.

Endre Gyozo Szabo from the National Authority for Hungarian Data Protection and Freedom of Information and Dariusz Kloza from Vrije Universiteit Brussel took the floor next. The fact that Kloza, in his very interesting presentation, illustrated the problem of forms and procedures of confidentiality of information, is worth emphasizing here.

The second section of the conference was called "Privacy enforcement in practice - International experiences in real life case handling", and it was focused on "real life" cases. In this session, attention was devoted to answering questions concerning the ways data protection authorities deal with barriers in privacy law enforcement, and possible applications of solutions which can use existing instruments and forms of co-operation and coordination among European Union data protection authorities under European Union legal frameworks.

Viljar Peep from the Estonian Data Protection Inspectorate was the first speaker in the second session, and he gave a presentation illustrating the problem of forms of cooperation between data protection authorities. Peep emphasized the question of the best form of cooperation for discussion and decision-making in the sphere of data protection cooperation, and offered the example of small bilateral and multilateral groups.

Peter Michael (Europol Joint Supervisory Body) took the floor next, emphasizing that one of the most important aspects of co-operation in the sphere of data protection is that people from different organizations, and from different countries, know each other, as it is very helpful for building this kind of co-operation. 
The following speakers were Marek Múčka, who presented the issue of biometrics in the context of different legal approaches, and Dimitar Gjeorgievski from the Macedonian Directorate for Personal Data Protection. It is worth mentioning that Gjeorgievski discussed the issue of exchanging good experiences in cooperation among data protection authorities. Moreover, in the second panel, Lahousissine Annis (CNDP, Morocco) and Alexander Hanff from Think Privacy Inc. provided interesting presentations.

The final session of the conference was "European and International cooperation in enforcing privacy - expectations and solutions for a reinforced co-operation", and was devoted to legislative and practical barriers to enforcing privacy. The following speakers presented their presentation during that session: Jacob Kohnstamm (Data Protection from the Netherlands), Hugh Stevenson from US FEDERAL Trade Commission, Maciej Groń (Ministry of Administration and Digitalization from Poland), Maciej Wiewórowski (Assistant European Data Protection), PhD Adam Bodnar (Helsinki Foundation for Human Rights), Professor Paul De Hert and Gertjan Boulet (Vrije Universiteit Brussels). It should be emphasized that all of the speakers from the third session focused not only on such problems as legislative and practical barriers to enforcing privacy, but they also tried to recognize the legal and non-legal constraints that DPAs face in connection with the enforcement of privacy and data protection legislation - from the point of view of both regulators and stakeholders.

The conference closed with a presentation of the new PHAEDRA project. After this presentation, the conference organizers thanked the guests for their participation at this major conference. 